\title{
Unsynchronized Resonance of Covalent Bonds in the Superconducting State
}

\author{
Marconi B. S. Costa, Cristiano C. Bastos and Antonio C. Pavão* \\ Departamento de Química Fundamental, Universidade Federal de Pernambuco, \\ 50670-901 Recife-PE, Brazil
}

Cálculos DFT em modelos de cluster de cupratos $\left(\mathrm{LaBa}_{2} \mathrm{Cu}_{3} \mathrm{O}_{6.7}, \mathrm{La}_{1.85} \mathrm{Sr}_{0.15} \mathrm{CuO}_{4}, \mathrm{YBa}_{2} \mathrm{Cu}_{3} \mathrm{O}_{7}\right.$, $\left.\mathrm{TlBa}_{2} \mathrm{Ca}_{2} \mathrm{Cu}_{3} \mathrm{O}_{8.78}, \mathrm{HgBa}_{2} \mathrm{Ca}_{2} \mathrm{Cu}_{3} \mathrm{O}_{8.27}\right)$, de sistemas metálicos $\left(\mathrm{Nb}_{3} \mathrm{Ge}, \mathrm{MgB}_{2}\right)$ e do pnictido $\mathrm{LaO}_{0.92} \mathrm{~F}_{0.08} \mathrm{FeAs}$ indicaram a ocorrência da ressonância não-sincronizada no estado supercondutor, como prevê a teoria RVB (resonating valence bond) de Pauling. Para os cupratos, a ressonância não-sincronizada envolve transferência de elétron entre átomos de $\mathrm{Cu}$, acompanhada pela redução da carga dos átomos $\mathrm{La}, \mathrm{Sr}, \mathrm{Y}$ e Ca. Para o $\mathrm{MgB}_{2}$, a transferência de elétron ocorre na camada do $\mathrm{Mg}$, enquanto a do $\mathrm{B}$ comporta-se como reservatório de cargas. Para $\mathrm{o} \mathrm{Nb}_{3} \mathrm{Ge}$, a ressonância ocorre entre átomos de Ge, que devem ser os responsáveis pela transferência de carga. Para o $\mathrm{LaO}_{0.92} \mathrm{~F}_{0.08} \mathrm{FeAs}$, ambas as camadas de $\mathrm{La}-\mathrm{O}$ e Fe-As estão envolvidas no mecanismo da supercondutividade. A observação de ressonâncias não-sincronizadas nestes sistemas fornece uma evidência em favor da RVB como uma teoria apropriada para a supercondutividade em altas temperaturas (high- $\mathrm{T}_{\mathrm{C}}$ ).

DFT calculations performed on different cluster models of cuprates $\left(\mathrm{LaBa}_{2} \mathrm{Cu}_{3} \mathrm{O}_{6.7}\right.$, $\left.\mathrm{La}_{1.85} \mathrm{Sr}_{0.15} \mathrm{CuO}_{4}, \mathrm{YBa}_{2} \mathrm{Cu}_{3} \mathrm{O}_{7}, \mathrm{TlBa}_{2} \mathrm{Ca}_{2} \mathrm{Cu}_{3} \mathrm{O}_{8.78}, \mathrm{HgBa}_{2} \mathrm{Ca}_{2} \mathrm{Cu}_{3} \mathrm{O}_{8.27}\right)$, metallic systems $\left(\mathrm{Nb}_{3} \mathrm{Ge}\right.$, $\mathrm{MgB}_{2}$ ) and the pnictide $\mathrm{LaO}_{0.92} \mathrm{~F}_{0.08} \mathrm{Fe}$ As made evident the occurrence of unsynchronized resonance of covalent bonds in the superconducting state, as predicted by Pauling's resonating valence bond (RVB) theory. For cuprates, the unsynchronized resonance involves electron transfer between $\mathrm{Cu}$ atoms accompanied by a decrease in the charge of the $\mathrm{La}, \mathrm{Sr}, \mathrm{Y}$ and $\mathrm{Ca}$ atoms. For $\mathrm{MgB}_{2}$, electron transfer occurs in the $\mathrm{Mg}$ layer, while the $\mathrm{B}$ layer behaves as charge reservoir. For $\mathrm{Nb}_{3} \mathrm{Ge}$, unsynchronized resonance occurs among the Ge atoms, which should be responsible for charge transfer. For $\mathrm{LaO}_{0.92} \mathrm{~F}_{0.08} \mathrm{FeAs}$, the results suggest that both $\mathrm{La}-\mathrm{O}$ and $\mathrm{Fe}-\mathrm{As}$ layers are involved in the mechanism of superconductivity. The identification of unsynchronized resonances in these systems provides evidence which supports RVB as a suitable theory for high-temperature superconductivity (high- $\mathrm{T}_{\mathrm{C}}$ ).

Keywords: RVB theory, superconductivity, DFT calculations

\section{Introduction}

\section{The RVB theory for superconductors}

The resonating valence bond theory (RVB) developed by L. Pauling about sixty years ago ${ }^{1}$ has proven to be a valuable and versatile tool in explaining electron transfer mechanisms, crystal structure and interatomic distances of alloys, intermetallic compounds, and transition metals complexes. Pauling also employed his theory to describe superconducting properties of metals, alloys, cuprates and fulleride systems in terms of their crystal structure and atomic composition. ${ }^{2}$ Pavão et al. ${ }^{3}$ have used the RVB theory to explain magnetism in metals,

*e-mail: pavao@ufpe.br adsorption and dissociation of small molecules on metallic surfaces,${ }^{4}$ chemical carcinogenesis, ${ }^{5}$ mechanism of the $\mathrm{O}_{4}$ formation, ${ }^{6}$ and conductivity in lithium clusters, ${ }^{7}$ as well as superconductivity in $\mathrm{YBCO}$ and $\mathrm{K}_{3} \mathrm{C}_{60},{ }^{8}$ demonstrating the versatility of this theory. ${ }^{9}$ Some other authors have also succeeded in using the RVB theory, ${ }^{10-12}$ including Anderson's studies on the RVB theory. ${ }^{13}$

The central concept of the RVB theory is related to the metallic bond, which is described as a shared-electron-pair covalent bond resonating among the available interatomic positions, and to the possession by each atom, or each of many atoms in the metallic phase, of an extra orbital - the so-called "metallic orbital" - in addition to the orbitals normally occupied by electrons. ${ }^{1}$ The metallic orbital allows for the unsynchronized resonance of covalent bonds by electron transfer from one atom to the next one, 
represented as $\mathrm{M}-\mathrm{M} \cdots \mathrm{M} \rightarrow \mathrm{M}^{+} \cdots \mathrm{M}^{0}-\mathrm{M}^{-}$, resulting in the stabilization of the system by means of resonance energy and charge separation, which is the conductor state. ${ }^{1}$

It is the electroneutrality principle ${ }^{1}$ that permits $\mathrm{M}^{+}, \mathrm{M}^{0}$, and $\mathrm{M}^{-}$but not charges larger than \pm 1 . The unsynchronized resonance energy is comparable in magnitude to the bond energy; the effect of thermal agitation, which temporarily lengthens some bonds and shortens others, interferes with the resonance of the bonds, explaining the scattering of electrons by phonons. ${ }^{1}$ Basing his work on the concept of unsynchronized resonance, Pauling classified superconductors into two classes: crest and trough. ${ }^{2}$ Crest superconductors are hypoelectronic elements, whereas trough superconductors are hyperelectronic elements. Hypoelectronic elements are electron-deficient atoms that can increase their valence by receiving electrons; in the neutral state, they have more bond orbitals than valence electrons. On the other hand, hyperelectronic elements are electron-excess atoms that can increase their valence by giving up an electron. These elements have more valence electrons than bond orbitals. In a crest superconductor there is an excess of negative charge associated with the phonon; on the other hand, there is a deficiency of negative charge associated with trough. Because it is electron pairs that travel with the phonon, the charge of the superconducting current in a crest superconductor travels with the crest of the waves. The reverse situation occurs in a trough superconductor. For the RVB theory, the high-temperature superconductivity fulfills two conditions: $(i)$ metallic conductivity and (ii) a mechanism that keeps electrons moving in the same direction. This mechanism in the BCS theory is the electron-phonon interaction. An alternative is provided in the RVB theory. The superconductor temperature is low due to electron-phonon scattering, the same mechanism that causes conductivity of metals to decrease with increasing temperature. To obtain high-Tc superconductors, electron scattering can be kept low by combining crest and trough superconductors. According to the RVB theory, this electron-phonon interaction occurs with unsynchronized resonance between $\mathrm{M}^{-}$and $\mathrm{M}^{0}$ in the crest and $\mathrm{M}^{0}$ and $\mathrm{M}^{+}$in the trough, resulting in greater stability for the crystal. ${ }^{2}$

In the present work, the DFT calculations on cuprates and metallic and iron pnictide systems demonstrate that the $\mathrm{M}^{+}, \mathrm{M}^{0}$ and $\mathrm{M}^{-}$states require the unsynchronized resonance of the covalent bonds in superconductors.

For cuprates, it was found that the depopulation of one or two oxygen sites along the copper-oxygen chains creates the $\mathrm{M}^{+}$and $\mathrm{M}^{-}$states and decreases the charge of the $\mathrm{La}, \mathrm{Sr}, \mathrm{Y}$ and $\mathrm{Ca}$, in agreement with the RVB theory. ${ }^{2}$ For $\mathrm{MgB}_{2}$, it was found that the unsynchronized resonance of covalent bonds occurs in the $\mathrm{Mg}$ layer, while the $\mathrm{B}$ layer behaves as a charge reservoir. For $\mathrm{Nb}_{3} \mathrm{Ge}$, the unsynchronized resonance involves only germanium atoms. For the $\mathrm{LaO}_{0.92} \mathrm{~F}_{0.08} \mathrm{FeAs}$ pnictide, substitution of oxygen by fluorine produces charge separation between $\mathrm{La}$ atoms, suggesting the involvement of the La-O layer in the superconductivity mechanism. The next sections present computational details of the calculations and discussions of the occurrence of unsynchronized resonance in the superconducting state.

\section{Calculations}

The calculations were carried out with BLYP gradientcorrected LDA density functional, ${ }^{14}$ as implemented in Gaussian03 computational code. ${ }^{15}$ BLYP density functional combines Becke exchange-energy functional with the Lee-Yang-Parr correlation-energy functional and provides appropriated energy values for metalcontaining compounds. ${ }^{14}$ The effective core potential (ECP) LanL1dz basis set of Hay and Wadt was used for all atoms. ${ }^{16}$ To minimize effects of loss of regularity and the presence of some kind of surface, the boundary atoms of the clusters are saturated with hydrogen atoms. This procedure prevents the dangling bonds, which would introduce excess of electrons into the cluster. Accordingly the clusters formulas are: $\mathrm{LaBa}_{2} \mathrm{Cu}_{16} \mathrm{O}_{24} \mathrm{H}_{40}$, $\mathrm{La}_{16} \mathrm{Sr}_{2} \mathrm{Cu}_{14} \mathrm{O}_{30} \mathrm{H}_{42}, \mathrm{YBa}_{2} \mathrm{Cu}_{16} \mathrm{O}_{20} \mathrm{H}_{40}, \mathrm{Tl}_{8} \mathrm{Ba}_{2} \mathrm{Ca}_{2} \mathrm{Cu}_{12} \mathrm{O}_{22} \mathrm{H}_{48}$, $\mathrm{Hg}_{8} \mathrm{Ba}_{2} \mathrm{Ca}_{2} \mathrm{Cu}_{12} \mathrm{O}_{22} \mathrm{H}_{48}, \mathrm{Nb}_{12} \mathrm{Ge}_{9} \mathrm{H}_{36}, \mathrm{Mg}_{21} \mathrm{~B}_{12} \mathrm{H}_{32}$, and $\mathrm{La}_{24} \mathrm{O}_{10} \mathrm{Fe}_{5} \mathrm{As}_{12} \mathrm{H}_{76}$. Hydrogen atoms were added at the limits of the cluster following the crystal directions $\mathrm{a}, \mathrm{b}$, and c. The metal-hydrogen bond length was taken as the sum of the covalent radii of the atoms. Figure 1 shows the cluster models used in the calculations. ${ }^{17-24}$

The cluster models were built by using the software PowderCell, ${ }^{25}$ a program that allows for the representation and manipulation of crystal structures and the calculation of the resulting $\mathrm{X}$-ray powder patterns. The $\mathrm{X}$-ray and neutron diffraction data for $\mathrm{LaBa}_{2} \mathrm{Cu}_{3} \mathrm{O}_{6.7},{ }^{17} \mathrm{La}_{1.85} \mathrm{Sr}_{0.15} \mathrm{CuO}_{4},{ }^{18}$ $\mathrm{YBa}_{2} \mathrm{Cu}_{3} \mathrm{O}_{7},{ }^{19} \mathrm{TlBa}_{2} \mathrm{Ca}_{2} \mathrm{Cu}_{3} \mathrm{O}_{8.78},{ }^{20} \mathrm{HgBa}_{2} \mathrm{Ca}_{2} \mathrm{Cu}_{3} \mathrm{O}_{8.27},{ }^{21}$ $\mathrm{Nb}_{3} \mathrm{Ge},{ }^{22} \mathrm{MgB}_{2},{ }^{23}$ and $\mathrm{LaO}_{0.92} \mathrm{~F}_{0.08} \mathrm{FeAs}^{24}$ were taken according to Rietveld refinement employed by the respective authors. This procedure ensures complete absence of defects in the clusters that were used in our calculations. Previous studies have demonstrated the effectiveness of this method, particularly in superconducting crystals. ${ }^{8}$

The oxygen vacancies in the $\mathrm{YBa}_{2} \mathrm{Cu}_{16} \mathrm{O}_{20} \mathrm{H}_{40}$ and $\mathrm{LaBa}_{2} \mathrm{Cu}_{16} \mathrm{O}_{24} \mathrm{H}_{40}$ clusters are positioned at the $\mathrm{O}(3)$ site. For $\mathrm{La}_{16} \mathrm{Sr}_{2} \mathrm{Cu}_{14} \mathrm{O}_{30} \mathrm{H}_{42}, \mathrm{Tl}_{8} \mathrm{Ba}_{2} \mathrm{Ca}_{2} \mathrm{Cu}_{12} \mathrm{O}_{22} \mathrm{H}_{48}$ and $\mathrm{Hg}_{8} \mathrm{~B}_{2} \mathrm{Ca}_{2} \mathrm{Cu}_{12} \mathrm{O}_{22} \mathrm{H}_{48}$ the oxygen vacancy is at the $\mathrm{O}(4)$ site. The lattice parameters for the defective cuprate 


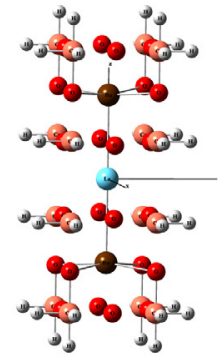

a)

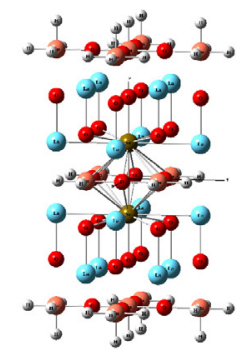

b)

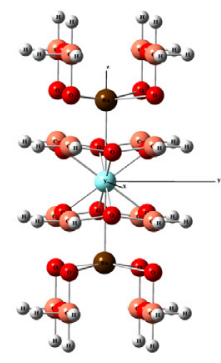

c)

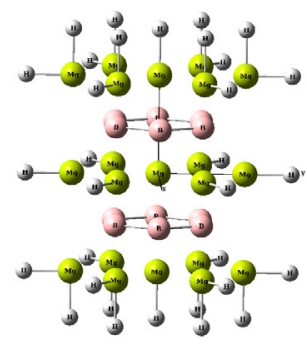

g)

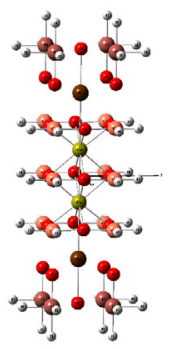

d)

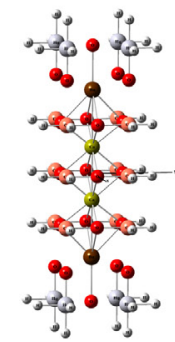

e)

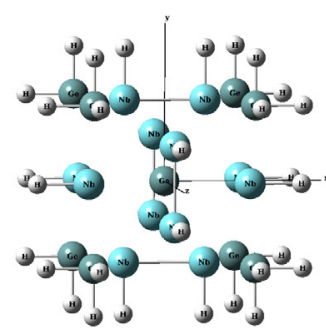

f)

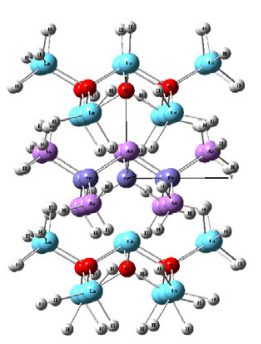

h)

Figure 1. Cluster models: a) $\mathrm{LaBa}_{2} \mathrm{Cu}_{16} \mathrm{O}_{24} \mathrm{H}_{40}$, b) $\mathrm{La}_{16} \mathrm{Sr}_{2} \mathrm{Cu}_{14} \mathrm{O}_{30} \mathrm{H}_{42}$, c) $\mathrm{YBa}_{2} \mathrm{Cu}_{16} \mathrm{O}_{20} \mathrm{H}_{40}$, d) $\mathrm{Tl}_{8} \mathrm{Ba}_{2} \mathrm{Ca}_{2} \mathrm{Cu}_{12} \mathrm{O}_{22} \mathrm{H}_{48}$, e) $\mathrm{Hg}_{8} \mathrm{Ba}_{2} \mathrm{Ca}_{2} \mathrm{Cu}_{12} \mathrm{O}_{22} \mathrm{H}_{48}$, f) $\mathrm{Nb}_{12} \mathrm{Ge}_{9} \mathrm{H}_{36}$, g) $\mathrm{Mg}_{21} \mathrm{~B}_{12} \mathrm{H}_{32}$ and h) $\mathrm{La}_{24} \mathrm{O}_{10} \mathrm{Fe}_{5} \mathrm{As}_{12} \mathrm{H}_{76}$. Legend: $\mathrm{La}$; $\mathrm{Ba}$; Cu; $\mathrm{C}$; $\mathrm{H} ; \mathrm{Sr}$; $\mathrm{Y}$; $\mathrm{Tl}$; $\mathrm{Ca}$; $\mathrm{Hg}$; $\mathrm{Nb} ; \mathrm{Ge}$; $\mathrm{Mg}$; $\mathrm{B}$; $\mathrm{Fe}$; $\mathrm{As}$.

clusters (with oxygen vacancies) are the same as those used for the fully oxygenated clusters. The superconducting copper ceramics are inhomogeneous systems containing both superconducting and nonsuperconducting regions that coexist in the same crystal as observed by scanning tunneling microscopy (STM) ${ }^{26}$ However, the X-ray or neutron diffraction measurements do not detect differences of the lattice parameters in the superconducting phase, where oxygen vacancies occur. ${ }^{17-21}$ This means that our results are analyzed in a relaxed system, where an average atom position is used. Our results clearly indicate that oxygen vacancy is responsible for dramatically changing the value of the band gap. ${ }^{8}$

\section{Results and Discussion}

According to the BCS theory, the superconducting energy gap $2 \Delta$ is originated from the electron-electron interaction via phonon. ${ }^{27}$ Tanaka $^{28}$ correlates the superconducting energy gap to the energy difference between the unrestricted Hartree-Fock singlet state and the triplet state. The agreement between experiments and calculated values is a first argument in favor the Tanaka's procedure. In addition, it is well-known that the transition from a normal to a superconducting state of a material is accompanied by main modifications in its electronic structure and not in its crystal structure. Thus, the first excited state corresponds to the normal state (in the triplet state there is no Cooper pairs), and the ground state corresponds to the superconducting state (in the singlet state Cooper pairs can be formed). However, the energy difference between these two states is a satisfactory evaluation of the superconducting gap. Following this procedure, the superconducting gap was correlated to the energy difference between the highest occupied molecular orbital and the lowest unoccupied molecular orbital $\left(\Delta_{\mathrm{HL}}\right.$ gap). Rather than performing unrestricted calculations, as in Tanaka's procedure, restricted closed-shell DFT calculations were performed in the present work.

Accordingly, the $\Delta_{\mathrm{HL}}$ value is a criterion for distinguishing the superconducting state. In our previous calculations, ${ }^{8}$ this same criterion was used to recognize the oxygen vacancy site responsible for the occurrence of superconductivity in YBCO systems. The occurrence of superconductivity in the $\mathrm{K}_{3} \mathrm{C}_{60}$ system was also identified by analyzing the variation of the $\Delta_{\mathrm{HL}}$ gap. ${ }^{8}$ Table 1 compares the $\Delta_{\mathrm{HL}}$ gap for the fully oxygenated cluster of cuprates to that containing one and two oxygen vacancies.

Table 1. Calculated $\Delta_{\mathrm{HL}}$ gap for cuprates (in meV)

\begin{tabular}{lcccc}
\hline System & $\begin{array}{c}\text { Fully } \\
\text { oxygenated }\end{array}$ & $\begin{array}{c}\text { One } \\
\text { vacancy }\end{array}$ & $\begin{array}{c}\text { Two } \\
\text { vacancies }\end{array}$ & Exp. \\
\hline $\mathrm{LaBa}_{2} \mathrm{Cu}_{16} \mathrm{O}_{24} \mathrm{H}_{40}$ & 293 & 18 & 8 & $10-23^{\mathrm{a}}$ \\
$\mathrm{La}_{16} \mathrm{Sr}_{2} \mathrm{Cu}_{14} \mathrm{O}_{30} \mathrm{H}_{42}$ & 104 & 45 & 12 & $2-13^{\mathrm{a}, \mathrm{b}}$ \\
$\mathrm{YBa}_{2} \mathrm{Cu}_{16} \mathrm{O}_{20} \mathrm{H}_{40}$ & 320 & 14 & 5 & $12-30^{\mathrm{b}}$ \\
$\mathrm{Tl}_{8} \mathrm{Ba}_{2} \mathrm{Ca}_{2} \mathrm{Cu}_{12} \mathrm{O}_{22} \mathrm{H}_{48}$ & 200 & 63 & 26 & $20-40^{\mathrm{b}}$ \\
$\mathrm{Hg}_{8} \mathrm{Ba}_{2} \mathrm{Ca}_{2} \mathrm{Cu}_{12} \mathrm{O}_{22} \mathrm{H}_{48}$ & 185 & 49 & 32 & $48-70^{\mathrm{b}}$ \\
\hline
\end{tabular}

${ }^{\mathrm{a}}$ Reference 29. ${ }^{\mathrm{b}}$ Reference 30. 
It is remarkable that the $\Delta_{\mathrm{HL}}$ gap of the cuprates clusters containing oxygen vacancies lies at the same range of the experimental gap. On the other hand, the $\Delta_{\mathrm{HL}}$ gap for the fully oxygenated clusters is in the order of hundreds of meV. This result indicates that the superconductivity is associated to oxygen vacancies in specific sites of the cuprate crystal, in agreement to experimental data. ${ }^{17-21,26}$

The calculated $\Delta_{\mathrm{HL}}$ gaps for the $\mathrm{Nb}_{3} \mathrm{Ge}, \mathrm{MgB}_{2}$ and $\mathrm{LaO}_{0.92} \mathrm{~F}_{0.08} \mathrm{Fe}$ As superconductors also compare well to the experimental values. ${ }^{31-33}$ For the $\mathrm{Nb}_{12} \mathrm{Ge}_{9} \mathrm{H}_{36}$ cluster, a gap of $4.5 \mathrm{meV}$ was obtained, very close to the experimental value, which varies between 3.8 and $4.2 \mathrm{meV} .{ }^{30,31}$ For the $\mathrm{Mg}_{21} \mathrm{~B}_{12} \mathrm{H}_{32}$ cluster, the calculated $\Delta_{\mathrm{HL}}$ value is $3 \mathrm{meV}$, which compares well to the experimental values of 2 and $7.5 \mathrm{meV}^{32}$ For the $\mathrm{LaO}_{0.92} \mathrm{~F}_{0.08} \mathrm{FeAs}$ superconductor, which has an experimental gap between 3.6 and $4.1 \mathrm{meV},{ }^{33}$ the calculated $\Delta_{\mathrm{HL}}$ gap of the undoped cluster $\left(\mathrm{La}_{24} \mathrm{O}_{10} \mathrm{Fe}_{5} \mathrm{As}_{12} \mathrm{H}_{76}\right)$ is $106 \mathrm{meV}$; however, it is reduced to $7 \mathrm{meV}$ for the fluorine doped cluster $\left(\mathrm{La}_{24} \mathrm{FO}_{9} \mathrm{Fe}_{5} \mathrm{As}_{12} \mathrm{H}_{76}\right)$.

Since the present DFT cluster calculations give very low $\Delta_{\mathrm{HL}}$ gaps, which according to our criterion distinguish the superconducting state, let us employ these calculations to identify the atoms involved in the unsynchronized resonances of the superconducting state by analysis of the atomic charge distribution. As predicted by the RVB theory, the occurrence of the $\mathrm{M}^{+}, \mathrm{M}^{0}$ and $\mathrm{M}^{-}$states for all superconducting systems was observed. In cuprates, unsynchronized resonances were identified only for clusters containing oxygen vacancies, in agreement with experiments. ${ }^{17-21}$ For the metallic systems $\mathrm{Nb}_{3} \mathrm{Ge}$ and $\mathrm{MgB}_{2}$, atomic charge distribution in accordance with the RVB predictions is found. For the pnictide system $\mathrm{LaO}_{0.92} \mathrm{~F}_{0.08} \mathrm{FeAs}$, unsynchronized resonances were observed only for the fluorine doping cluster, in agreement with the experimental data. ${ }^{24}$ Therefore, for all systems studied, unsynchronized resonances of covalent bonds were identified in the superconducting state.

For cuprates, the alternation of the covalent bond and no-bond in the chain give rise to synchronized resonance corresponding to the movement of electron pairs along the string of atoms in synchronism:

$\cdots \mathrm{Cu}-\mathrm{O} \cdots \mathrm{Cu}-\mathrm{O} \cdots \mathrm{Cu}-\mathrm{O} \cdots \rightarrow \cdots \mathrm{O}-\mathrm{Cu} \cdots \mathrm{O}-\mathrm{Cu} \cdots \mathrm{O}-\mathrm{Cu} \cdots$

With the synchronized resonance there is no charge separation, which would lead to an insulator state. However, the oxygen vacancy (indicated by... ) interrupts this atom sequence, giving rise to charge separation and to unsynchronized resonance:

$\cdots \mathrm{Cu}-\mathrm{O} \cdots \mathrm{Cu} \cdots \mathrm{Cu}-\mathrm{O} \cdots \rightarrow \cdots \mathrm{O}-\mathrm{Cu}^{-} \cdots \mathrm{Cu}^{+} \cdots \mathrm{O}-\mathrm{Cu} \cdots$
Table 2 presents the calculated Mülliken atomic charge of copper atoms adjacent to the oxygen vacancy. As can be observed, these atomic charges follow the scheme of the unsynchronized resonance. Even though Mülliken analysis has limitations due to significant basis set dependence and separation of the atomic electron population, it was employed here instead of Bader charge analysis, method that would be more suitable when DFT is used. The reason is that there are restrictions in the Gaussian code in calculating systems with a very unusual topology, which always results in errors in Bader atomic charges of less than $2.0 \times 10^{-4}$ per atom..$^{15}$ Nevertheless, by considering relative values, the Mülliken atomic charges are appropriated to identify the unsynchronized resonances predicted by the RVB theory. ${ }^{2,8}$

Table 2. Atomic charge distribution for cuprates

\begin{tabular}{|c|c|c|c|c|c|}
\hline \multirow{2}{*}{ Cluster } & \multicolumn{3}{|c|}{ Atomic charge } & \multirow{2}{*}{ tom } & \multirow{2}{*}{$\begin{array}{l}\text { Atomi } \\
\text { charge }\end{array}$} \\
\hline & $\mathrm{Cu}^{+}$ & $\mathrm{Cu}^{0}$ & $\mathrm{Cu}^{-}$ & & \\
\hline${ }^{a} \mathrm{LaBa}_{2} \mathrm{Cu}_{16} \mathrm{O}_{24} \mathrm{H}_{40}$ & & 0.120 & & $\mathrm{La}$ & 1.510 \\
\hline${ }^{b} \mathrm{LaBa}_{2} \mathrm{Cu}_{16} \mathrm{O}_{23} \mathrm{H}_{40}$ & 0.161 & - & 0.055 & $\mathrm{La}$ & .502 \\
\hline${ }^{1} \mathrm{LaBa}_{2} \mathrm{Cu}_{16} \mathrm{O}_{22} \mathrm{H}_{40}$ & 0.149 & - & 0.052 & $\mathrm{La}$ & 1.500 \\
\hline${ }^{2} \mathrm{La}_{16} \mathrm{Sr}_{2} \mathrm{Cu}_{14} \mathrm{O}_{30} \mathrm{H}$ & - & 1.132 & - & $\mathrm{Sr}$ & 2.423 \\
\hline${ }^{b} \mathrm{La}_{16} \mathrm{Sr}_{2} \mathrm{Cu}_{14} \mathrm{O}_{29} \mathrm{I}$ & 1.209 & - & 0.430 & $\mathrm{Sr}$ & 2.288 \\
\hline${ }^{2} \mathrm{YBa}_{2} \mathrm{Cu}_{16} \mathrm{O}_{20} \mathrm{H}_{40}$ & - & 0.124 & - & $\mathrm{Y}$ & 1.905 \\
\hline${ }^{\mathrm{b}} \mathrm{YBa}_{2} \mathrm{Cu}_{10} \mathrm{O}_{19} \mathrm{H}$ & 0.081 & - & 0.025 & $\mathrm{Y}$ & 1.862 \\
\hline${ }^{2} \mathrm{YBa}_{2} \mathrm{Cu}_{10} \mathrm{O}_{18} \mathrm{H}_{40}$ & 0.080 & - & -0.040 & $\mathrm{Y}$ & 1.737 \\
\hline${ }^{\mathrm{a}} \mathrm{Tl}$ & - & 0.242 & - & $\mathrm{Ca}$ & 2.071 \\
\hline${ }^{\mathrm{b}} \mathrm{Tl}_{8} \mathrm{I}$ & 0.526 & - & 0.184 & $\mathrm{Ca}$ & .024 \\
\hline${ }^{C} \mathrm{Tl}_{8} \mathrm{Ba}_{2} \mathrm{Ca}_{2} \mathrm{Cu}_{12} \mathrm{O}_{20} \mathrm{H}_{48}$ & 0.128 & - & 0.045 & $\mathrm{Ca}$ & 1.939 \\
\hline${ }^{a} \mathrm{Hg}_{8}$ & - & 0.010 & - & $\mathrm{Ca}$ & 55 \\
\hline${ }^{b} \mathrm{Hg}_{8} \mathrm{Ba}_{2} \mathrm{Ca}_{2} \mathrm{C}$ & 0.130 & - & -0.004 & $\mathrm{Ca}$ & 1.948 \\
\hline${ }^{1} \mathrm{Hg}_{8} \mathrm{Ba}_{2} \mathrm{Ca}_{2} \mathrm{Cu}_{12} \mathrm{O}_{20} \mathrm{H}$ & 0.126 & - & 0.036 & $\mathrm{Ca}$ & 1.939 \\
\hline
\end{tabular}

afully oxygenated; bone oxygen vacancy; 'two oxygen vacancies.

Table 2 shows that copper atoms have different charges only in presence of oxygen vacancies. For example, in the $\mathrm{LaBa}_{2} \mathrm{Cu}_{16} \mathrm{O}_{24} \mathrm{H}_{40}$ fully oxygenated cluster (no vacancy), the copper atomic charge is $+0.120 \mathrm{e}$, but copper atoms adjacent to the oxygen vacancy have charges $0.161 \mathrm{e}\left(\mathrm{M}^{+}\right)$ and $0.055 \mathrm{e}\left(\mathrm{M}^{0}\right)$, indicating electron transfer and some dismutation of $2 \mathrm{M}$ to $\mathrm{M}^{+}$and $\mathrm{M}^{0}$, in agreement with the unsynchronized resonating covalent bond scheme. This behavior is observed for all of the cuprate clusters. Table 2 also shows the decrease of the charge of the La, Sr, Y, and $\mathrm{Ca}$ atoms with the oxygen vacancies. Such reduction of the atomic charges reveals the interaction of the $\mathrm{Cu}-\mathrm{O}$ layers with the $\mathrm{La}, \mathrm{Sr}, \mathrm{Y}$, and Ca metals, in agreement with the RVB predictions. ${ }^{2}$ Pauling pointed out that extra charges received by the $\mathrm{La}, \mathrm{Sr}, \mathrm{Y}$, and $\mathrm{Ca}$ atoms cause tighter binding 
and greater local density, the so-called phonon crest. ${ }^{2}$ In the $\mathrm{Cu}-\mathrm{O}$ superconducting layer, the extra charges lead to a decrease in bonding and local density, the phonon trough. This mechanism provides an explanation for the decreases in the amount of electron-phonon scattering, once the strength of the electron-phonon interaction becomes smaller with the crest-trough superconductors combination. $^{2}$

For the $\mathrm{Mg}_{21} \mathrm{~B}_{12} \mathrm{H}_{32}$ cluster, it was found that the unsynchronized resonance of covalent bonds occurs in the Mg layer, whereas the B layer behaves as a charge reservoir. The calculated atomic charges of magnesium vary from $+0.513\left(\mathrm{M}^{+}\right)$to $-0.090\left(\mathrm{M}^{0}\right)$, as boron atoms are $-0.138\left(\mathrm{M}^{-}\right)$. Akimitsu and Muranaka ${ }^{34}$ found that the valence of the whole boron $2 \mathrm{D}$ sheet changes from neutral to monovalent, increasing valence by one unit below $\mathrm{T}_{\mathrm{C}}$. Such variation is also observed in the present calculations, which show that the boron atom becomes negative in the superconducting state.

For the $\mathrm{Nb}_{12} \mathrm{Ge}_{9} \mathrm{H}_{36}$ cluster, the atomic charge distribution indicates unsynchronized resonance among germanium atoms, as showed in Figure 2. According Cohen et $a l^{35}$ the charge transfer from $\mathrm{Ge}$ to $\mathrm{Nb}$ is not prominent, in agreement with our calculations that show charge transfer between Ge atoms $\left(+1.458\left(\mathrm{M}^{+}\right)\right.$and $\left.-0.171\left(\mathrm{M}^{-}\right)\right)$whereas $\mathrm{Nb}$ atoms remain (almost) neutral. The RVB charge transfer mechanism can be represented by the unsynchronized resonance: $\mathrm{Ge}-\mathrm{Nb} \cdots \mathrm{Ge} \rightarrow \mathrm{Ge}^{+} \cdots \mathrm{Nb}-\mathrm{Ge}^{-}$.

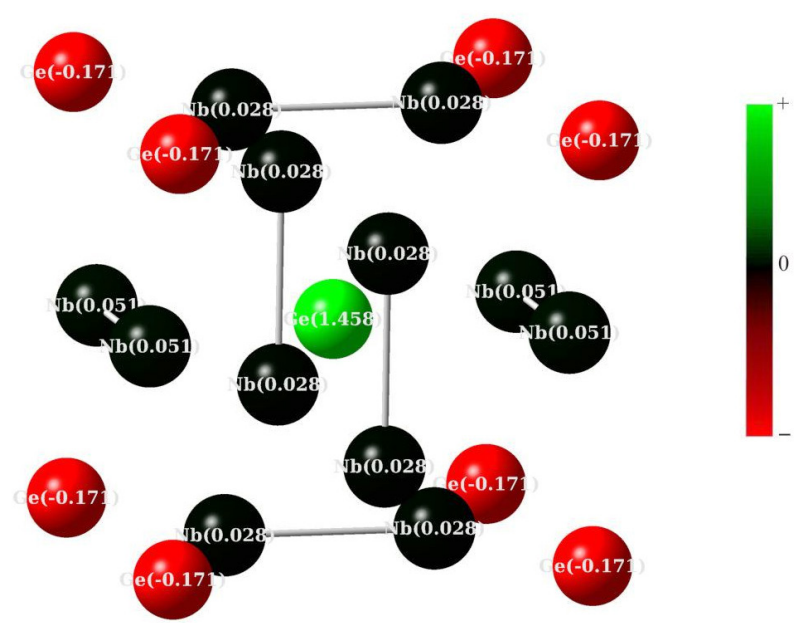

Figure 2. Mülliken atomic charge distribution in the $\mathrm{Nb}_{12} \mathrm{Ge}_{9} \mathrm{H}_{36}$ cluster. Black for $\mathrm{Nb}$ neutral atoms, red for negative and green for positive $\mathrm{Ge}$ atoms.

Germanium is a trough superconductor ${ }^{2,36}$ and would increase its valence in a region where there is electrons deficiency, and decrease its valence in a region where there is excess of electrons. An electron wave would consequently result in the lattice to contract in the electron extra region and to expand in the region where there is a deficient electron, so that the additional electrons would ride trough in the phonon. ${ }^{2}$ Niobium is a crest superconductor, and the situation is reversed. Crest-trough superconducting combination results in greater $\mathrm{T}_{\mathrm{C}}$ and enhanced performance of the material. ${ }^{2}$

Calculations on the pnictide clusters show that the fluorine doping leads to charge distribution consistent with the unsynchronized resonating covalent bond scheme. Unsynchronized resonance in the $\mathrm{Fe}-\mathrm{As}$ layer was found, in agreement with Takahashi et al, ${ }^{37}$ suggesting superconductivity as occurring in the layer. For the undoped cluster $\left(\mathrm{La}_{24} \mathrm{O}_{10} \mathrm{Fe}_{5} \mathrm{As}_{12} \mathrm{H}_{76}\right)$ there is no charge separation between the La atoms, but if oxygen is substituted by fluorine there is charge separation among the La atoms (+2.151 and -0.204), suggesting the involvement of $\mathrm{La}-\mathrm{O}$ layer in the superconductivity mechanism.

\section{Conclusions}

This work concludes that the present DFT calculations of the atomic charge distribution in different superconducting systems support the idea that the unsynchronized resonance of covalent bonds confers high-superconductivity properties, as predicted by Pauling. For cuprates, it was found that superconductivity requires oxygen vacancies along the copper-oxygen chain, which leads to electron transfer between $\mathrm{Cu}$ atoms and to charge decrease of the $\mathrm{La}, \mathrm{Sr}, \mathrm{Y}$ and $\mathrm{Ca}$ atoms. For $\mathrm{MgB}_{2}$, it is found that the unsynchronized resonance of covalent bonds occurs in the $\mathrm{Mg}$ layer, whereas the B layer behaves as a charge reservoir. For $\mathrm{Nb}_{3} \mathrm{Ge}$, unsynchronized resonance of covalent bonds occurs among the germanium atoms, which would be responsible for the charge carrier. For the $\mathrm{LaO}_{0.92} \mathrm{~F}_{0.08} \mathrm{FeAs}$ pnictide, results suggest that the $\mathrm{Fe}-\mathrm{As}$ layer as well as the $\mathrm{La}-\mathrm{O}$ is involved in the superconductivity mechanism.

\section{Acknowledgments}

This work was carried out with the support of Conselho Nacional de Desenvolvimento Científico e Tecnológico (CNPq), Brazil. The authors would like to acknowledge the Centro Nacional de Processamento de Alto Desempenho, São Paulo (CENAPAD-SP), Brazil.

\section{References}

1. Pauling, L.; Nature 1948, 161, 1019; ibid.; J. Chem. Soc. 1948, 1461; ibid.; Proc. R. Soc. A 1949, 196, 343; ibid.; Nature 1961, 189, 656; ibid.; J. Solid State Chem. 1984, 54, 297. 
2. Pauling, L.; Proc. Natl. Acad. Sci. U. S. A. 1968, 60, 59; ibid.; Phys. Rev. Lett. 1987, 59, 225; ibid. In High Temperature Superconductors; Gordon and Breach Scientific Publishers: New York, 1989; ibid.; Proc. Natl. Acad. Sci. U. S. A.1991, 88, 9208.

3. Pavão, A. C.; Santos J. R. S.; Taft, C. A.; Mol. Simul. 2009, 35, 287; Pavão, A. C.; Taft, C. A.; Hammond, B. L.; Lester, W. A.; Phys. Rev. B: Condens. Matter Mater. Phys. 1989, 40, 2879.

4. Ferreira, J. V.; Pavão, A. C.; Surf. Sci. 2008, 602, 1964.

5. Leão, M. B. C.; Pavão, A. C.; Taft, C. A.; Espinoza, V. A. A.; Bulnes, E. P. J.; THEOCHEM 2005, 719, 129.

6. Paula, J. C. F.; Pavão, A. C.; Taft, C. A.; THEOCHEM 2004, 713, 33; Pavão, A. C.; Paula, J. C. F.; Custódio, R.; Taft, C. A.; Chem. Phys. Lett. 2003, 370, 789.

7. Mohallem, J. R.; Vianna, R. O.; Quintão, A. D.; Pavão, A. C.; McWeeny, R.; Z. Phys. D: At., Mol. Clusters 1997, 42, 135.

8. Bastos, C. C.; Costa, M. B. S.; Pavão, A. C.; Int. J. Quantum Chem. 2010, 110, 2088; Rocha, J. A. M. R.; Pavão, A. C.; Phys. C (Amsterdam, Neth.) 2004, 411, 148; Costa, M. B. S.; Pavão, A. C.; Rev. Bras. Ens. Fis. 2012, 34, 2602; Costa, M. B. S.; Barros, K. A.; Rev. Virtual Quim. 2012, 4, 130.

9. Pavão, A. C.; Taft, C. A.; Guimarães, T. C. F.; Leão, M. B. C.; Mohallem, J. R.; Lester, J. W. A.; J. Phys. Chem. A 2001, 105, 5.

10. Liao C. N.; Chern, C. H.; J. Magn. Magn. Mater. 2011, 323, 232; Liu, J.; Ma, T.; Tong, H.; Luo, W.; Yan, M.; J. Magn. Magn. Mater. 2010, 322, 940.

11. Yao, Y.; Tse, J. S.; Klug, D. D.; Phys. Rev. B: Condens. Matter Mater. Phys. 2009, 80, 094106; Phillips, J. C.; Chem. Phys. Lett. 2008, 451, 98; Krasinkova, M. V.; Phys. C (Amsterdam, Neth.) 2006, 449, 33; Sachdev, S.; Rev. Mod. Phys. 2003, 75, 913.

12. Nissenbaum, D.; Spanu, L.; Attaccalite, C.; Barbiellini, B.; Bansil, A.; Phys. Rev. B: Condens. Matter Mater. Phys. 2009, 79, 035416; Harcourt, R. D.; Styles, M. L.; J. Phys. Chem. A 2003, 107, 3877; Marchi, M.; Azadi, S.; Casula, M.; Sorella, S.; J. Chem. Phys. 2009, 131, 154116.

13. Anderson, P. W.; Phys. Today 2008, 61, 8.

14. Becke, A. D.; Phys. Rev. A 1988, 38, 3098; Lee, C.; Yang, W.; Parr, R. G.; Phys. Rev. B: Condens. Matter Mater. Phys. 1988, 37, 785; Miehlich, B.; Savin, A.; Stoll, H.; Preuss, H.; Chem. Phys. Lett. 1989, 157, 200; Medina, J.; Coss, R.; Tapia, A.; Canto, G.; Eur. Phys. J. B 2010, 76, 427; Massobrio, C.; Micoulaut, M.; Salmon, P. S.; Solid State Sci. 2010, 12, 199.

15. Frisch, M. J.; Trucks, G. W.; Schlegel, H. B.; Scuseria, G. E.; Robb, M. A.; Cheeseman, J. R.; Montgomery, Jr., J. A.; Vreven, T.; Kudin, K. N.; Burant, J. C.; Millam, J. M.; Iyengar, S. S.; Tomasi, J.; Barone, V.; Mennucci, B.; Cossi, M.; Scalmani, G.; Rega, N.; Petersson, G. A.; Nakatsuji, H.; Hada, M.; Ehara, M.; Toyota, K.; Fukuda, R.; Hasegawa, J.; Ishida, M.; Nakajima, T.; Honda, Y.; Kitao, O.; Nakai, H.; Klene, M.; Li, X.; Knox, J. E.; Hratchian, H. P.; Cross, J. B.; Bakken, V.; Adamo, C.; Jaramillo, J.; Gomperts, R.; Stratmann, R. E.; Yazyev, O.;
Austin, A. J.; Cammi, R.; Pomelli, C.; Ochterski, J. W.; Ayala, P. Y.; Morokuma, K.; Voth, G. A.; Salvador, P.; Dannenberg, J. J.; Zakrzewski, V. G.; Dapprich, S.; Daniels, A. D.; Strain, M. C.; Farkas, O.; Malick, D. K.; Rabuck, A. D.; Raghavachari, K.; Foresman, J. B.; Ortiz, J. V.; Cui, Q.; Baboul, A. G.; Clifford, S.; Cioslowski, J.; Stefanov, B. B.; Liu, G.; Liashenko, A.; Piskorz, P.; Komaromi, I.; Martin, R. L.; Fox, D. J.; Keith, T.; A1-Laham, M. A.; Peng, C. Y.; Nanayakkara, A.; Challacombe, M.; Gill, P. M. W.; Johnson, B.; Chen, W.; Wong, M. W.; Gonzalez, C.; Pople, J. A.; Gaussian 03, Revision D.01; Gaussian, Inc.: Pittsburg, PA, 2003.

16. Hay, P. J.; Wadt, W. R.; J. Chem. Phys. 1985, 82, 270; ibid. 1985, 82, 284; ibid. 1985, 82, 299; Dunning, T. H.; Hay, P. J.; Modern Theoretical Chemistry, Plenum: New York, 1976.

17. Izumi, M.; Uchinokura, K.; Maeda, A.; Tanaka, S.; Jpn. J. Appl. Phys. 1987, 26, L1555.

18. Radaelli, P. G.; Hinks, D. G.; Mitchell, A. W.; Hunter, B. A.; Wagner, J. L.; Dabrowski, B.; Vandervoort, K. G.; Viswanathan, H. K.; Jorgensen, J. D.; Phys. Rev. B: Condens. Matter Mater. Phys. 1994, 49, 4163.

19. Calamiotou, M.; Gantis, A.; Margiolaki, I.; Palles, D.; Siranidi, E.; Liarokapis, E.; J. Phys.: Condens. Matter 2008, 20, 395224.

20. Mikusu, S.; Takami, S.; Tokiwa, K.; Takeuchi, K.; Iyo, A.; Tanaka, Y.; Watanabe, T.; Supercond. Sci. Technol. 2008, 21, 085014.

21. Wagner, J. L.; Hunter, B. A.; Hinks, D. G.; Jorgensen, J. D.; Phys. Rev. B: Condens. Matter Mater. Phys. 1995, 51, 15407.

22. Matthias, B. T.; Geballe, T. H.; Willens, R. H.; Corenzwit, E.; Hull, G. W.; Phys. Rev. 1965, 139, A1501; Gavaler, J. R.; Appl. Phys. Lett. 1973, 23, 480; Poole, C. P.; Superconductivity, $2^{\text {nd }}$ ed., Elsevier: Holanda, 2007.

23. Nakagawa, N.; Muranaka, T.; Zenitani, Y.; Akimitsu, J.; Nature 2001, 410, 63; Jones, M. E.; Marsh, R. E.; J. Am. Chem. Soc. 1954, 76, 1434.

24. Cruz, C.; Huang, Q.; Lynn, J. W.; Li, J. Y.; Ratcliff, W.; Zarestky, J. L.; Mook, H. A.; Chen, G. F.; Luo, J. L.; Wang, N. L.; Dai, P. C.; Nature 2008, 453, 899.

25. Kraus, W.; Nolze, G.; J. Appl. Crystallogr. 1996, 29, 301.

26. Lang, K. M.; Nature 2002, 415, 412.

27. Bardeen, J.; Cooper, L. N.; Schrieffer, J. R.; Phys. Rev. 1957, 108, 1175.

28. Tanaka, J.; Phys. C (Amsterdam, Neth.) 2007, 463,194.

29. Valla, T.; Fedorov, A. V.; Lee, J.; Davis, J. C.; Gul, G. D.; Science 2006, 314, 1914; Suga, M.; Nishino, T.; Tarutani, Y.; Takagi, K.; Phys. C (Amsterdam, Neth.) 1991, 185, 2573.

30. Poole, C.; Farach, H. A.; Creswick, R. J.; Prozorov, R.; Superconductivity, $2^{\text {nd }}$ ed., Elsevier: Amsterdam, 2007; Okawa, M.; Ishizaka, K.; Uchiyama, H.; Tadatomo, H.; Masui, T.; Tajima, S.; Wang, X. Y.; Chen, C. T.; Watanabe, S.; Chainani, A.; Saitoh, T.; Shin, S.; Phys. C (Amsterdam, Neth.) 2010, 470, S62; Giubileo, F.; Jossa, A.; Bobba, F.; Akimenko, 
A. I.; Malandrino, G.; Perdicaro, L. M.S.; Fragala, I. L.; Cucolo, A. M.; Phys. C (Amsterdam, Neth.) 2002, 367, 170.

31. Kihlstrom, K. E.; Mael, D.; Geballe, T. H.; Phys. Rev. B: Condens. Matter Mater. Phys. 1984, 29, 150; Stewart, G. R.; Newkirk, L. R.; Valencia, F. A.; Solid State Commun. 1978, 26, 417; Gavaler, J. R.; Janocko, M. A.; Jones, C. J.; Appl. Phys. Lett. 1973, 23, 480.

32. Tarantini, C.; Affronte, M.; Ferdeghini, C.; Manfrinetti, P.; Braccini, V.; Lehmann, E.; Putti, M.; Phys. C (Amsterdam, Neth.) 2007, 460, 560; Buzea, C.; Yamashita, T.; Supercond. Sci. Technol. 2001, 14, R115; Giubileo, F.; Roditchev, D.; Sacks, W.; Lamy, R.; Thanh, D. X.; Klein, J.; Miraglia, S.; Fruchart, D.; Marcus, J.; Monod, P.; Phys. Rev. Lett. 2001, 87, 177008.

33. Sato, T.; Souma, S.; Nakayama, K.; Terashima, K.; Sugawara, K.; Takahashi, T.; Kamihara, Y.; Hirano, M.; Hosono, H.;
J. Phys. Soc. Jpn. 2008, 77, 063708; Qiu, T.; Kofu, M.; Bao, W.; Lee, S. H.; Huang, Q.; Yildirim, T.; Copley, J. R. D.; Lynn, J. W.; Wu, T.; Wu, G.; Chen, X. H.; Phys. Rev. B: Condens. Matter Mater. Phys. 2008, 78, 052508.

34. Akimitsu, J.; Muranaka, T.; Phys. C (Amsterdam, Neth.) 2003, $388,98$.

35. Ho, K. M.; Pickett, W. E.; Cohen, M. L.; Phys. Rev. Lett. 1978, 41,580 .

36. Narlikar, A. V.; Frontiers in Superconducting Materials, Springer-Verlag: Berlin, 2005.

37. Takahashi, H.; Igawa, K.; Ariil, K.; Kamihara, Y.; Hirano, M.; Hosono, H.; Nature 2008, 453, 376.

Submitted: October 6, 2011

Published online: June 21, 2012 